\begin{tabular}{|c|c|c|}
\hline \multirow{2}{*}{$\begin{array}{l}\text { BENTHAM OPEN } \\
\text { CrossMark }\end{array}$} & $\begin{array}{c}\text { The Open Construction and Building } \\
\text { Technology Journal }\end{array}$ & $\begin{array}{l}\text { The Open } \\
\text { Construction \& Building } \\
\text { Technology lournal }\end{array}$ \\
\hline & $\begin{array}{l}\text { Content list available at: www.benthamopen.com/ТOBCTJ/ } \\
\text { DOI: } 10.2174 / 1874836801610010189\end{array}$ & 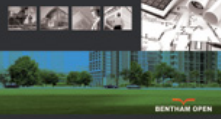 \\
\hline
\end{tabular}

\title{
Editorial
}

\section{Advances in Masonry Materials and Structures: Experimental \& Numerical Modelling Aspects}

\begin{abstract}
Masonry is a combination of units such as stones, bricks or concrete blocks usually laid in a cementitious or lime mortar. It is probably the oldest material used in construction and has proven to be both simple to build and durable. In spite of its simplicity of construction, the analysis of the mechanical behaviour of masonry structures remains a challenge. Masonry is a brittle, anisotropic, composite material that exhibits distinct directional properties due to the mortar joints which act as planes of weakness. It is the presence of mortar joints in a masonry structure, however simple, that create a resistance to tensile stresses that is markedly less than the material's resistance to compression. When subjected to very low levels of stresses, masonry behaves approximately in a linear elastic manner. The behaviour of masonry becomes increasingly non-linear after the formation of cracks and the subsequent redistribution of stress through the uncracked material as the structure approaches collapse. The behaviour of masonry is complicated further by the inherent variations in the constituent materials, variations in workmanship, the effects of deterioration caused by weathering processes and the development of other defects during the life of the masonry structure. Given the complexity of masonry behaviour, both experimental and numerical studies needs to be employed to understand the behaviour of these many different forms of masonry construction and inform decisions concerning maintenance, management of safety risks, assessment of levels of safety and the need for repair and/or strengthening. Also, a significant part of masonry structures are located in seismic regions, where earthquakes have exposed. The response of masonry structures to seismic excitations is still not well understood and thus extremely hard to predict. This problem is very challenging and it has also been addressed in this special issue.
\end{abstract}

The thematic issue on "Advances in Masonry Materials and Structures: Experimental \& Numerical Modelling Aspects" comprises of eleven contributions from leading international research workers and practitioners. Contributions cover a wide range of experimental and computational techniques; the later includes analysis at different levels of sophistication and methodological approaches.

The paper by Kappos and Papanikolaou (2016) focuses on the non-linear dynamic analysis for masonry and proposes a recent and innovative procedure that can be used for the seismic assessment of unreinforced masonry buildings. The procedure proposed by the authors introduces an equivalent frame model of a masonry building. A non-linear dynamic response history analysis used for a set of input ground motions scaled to different levels of earthquake intensity. In this way, the response of the structure up to failure captured. The results of this study are then used to derive a series of fragility curves for the different damage states. On the basis of inelastic deformation criteria, alternative sets of definitions of these damage states were used. The methodology proposed herein applied to a masonry building representative of Southern European practice, and analysed in both its original condition as well as after applying a series of different retrofitting schemes, typical of those implemented in pre-earthquake strengthening programmes. The article should be of particular interests to practitioners and design engineers assessing masonry structures.

The application of discrete element method for the dynamic analysis of masonry structures has been addressed by Lemos (2016). Although discrete elements have been mostly effective in the study of simple constructions and structural components, such as columns or walls, these are now increasingly being extended to more complex problems. In this paper, numerical issues of the discrete element method were examined, including contact models, calculation of natural frequencies, time stepping algorithms, damping and boundary conditions to illustrate the model capabilities and 
the various issues that may arise in applied studies. The author concludes that the ability of discrete element method to represent the essential features of the observed failure modes of masonry structures makes them an important tool in seismic analysis.

In their paper, Szakály et al. (2016) also used the discrete element method and investigated the influence of four different bond patterns (e.g. English bond, diagonal herringbone pattern, X-pattern, and V-pattern) on the shear resistance and failure mode of masonry wall panels. The authors observed that walls with herringbone (i.e. nonsymmetric) pattern turned out to be rather sensitive to the direction of the shear load. However, when vertical bricks included in the construction of the wall panels, does not necessarily increase their shear resistance.

The paper by Almac et al. (2016) evaluated the structural assessment of old and deteriorating stone columns in a historic masonry structure using the Finite Element Method (FEM). The columns contained a significant non-uniform erosion as well as deep local cavities, which led to formations of significant stress concentrations. An interesting feature of this work being the use of modern 3D laser scanner equipment and were able to capture millions of points from the surface of the deteriorated columns with high accuracy and extrapolate to construct the digital 3D shape of the elements which was later used in the FE code.

Christou and Elliotis (2016) highlighted the necessity of maintenance, repair, retrofit and restoration of stone masonry structures. The authors described the various types of natural stones, the most commonly used construction methods as well as methods for the retrofit of stone masonry structures. This article should be of particular interest to practitioners and engineers needed to assess and retrofit complex stone masonry structures.

Gattulli et al. (2016) summarizes the findings of the on-going design phase to develop smart strengthening systems to preserve existing and, in particular, ancient architectural heritage structures subjected to seismic loads. A real-scale experimental work combined with advanced finite element simulations undertaken to assess the suitability of an innovative seismic retrofitting technique for masonry walls and vaults strengthened by Glass Fiber Reinforced Polymer textile grids (HLM-GFRP) embedding new sensing systems as fiber optical sensors. The proposed approach suggests that measurements from the sensors can also be used as early warning on structural safety.

Theodossopoulos et al. (2016) provided an insight into the structural performance of Scottish barrel vaults of the $15^{\text {th }}$ Century. A series of scaled models accompanied with finite element simulations were undertaken to assess the effect of boundary conditions like asymmetric spread or settlement of one edge at both free and braced with gables (diaphragms) vaults. Information derived from this study could potentially be useful for understanding the development of crack patterns and collapse mechanisms and inform decisions concerning the maintenance needs, management of safety risks, assessment of levels of safety and the need for repair or strengthening.

The sensitivity of advanced and sophisticated methods of analysis to material parameters and geometry of the structure has been highlighted by D'Ambra et al. (2016). Masonry nonlinear mechanical properties such as the fracture energy, crucial for instance in the definition of post peak behaviour and ductility of masonry, have a crucial role at the single panel scale level analysis, while their impact is less crucial on the behaviour of entire masonry structure. A methodology has been developed by the authors able to calibrate a constitutive relationship for the description of the structural response of tuff masonry buildings subjected to monotonic actions. The calibration of the constitutive relationships for the numerical model carried out through the development of pushover analyses and results obtained compared to that from the experimental tests. The extended scope of this research was the evaluation of professional oriented analysis methods to deal with real structures, with wide dimensions like as the aggregates, for fast but reliable vulnerability evaluations. In this direction, in the future, further calibrated constitutive relationships will be provided for different masonry structures constructed with clay bricks and natural stone.

The last two contributions feature prominently the powerful theorems of plastic limit analysis for masonry constructions. Contestabile et al. (2016) investigated an application of the safe - unsafe theorem of Limit Analysis, adopted from the so called masonry-like model that is essentially the model of Jacques Heyman describing Rigid NoTension materials, to study the equilibrium of cross vault of unequal rise or those constructed on arches, such as those of some Romanesque and Gothic churches, under the effect of pure vertical loading. As a case study, the lateral cross vaults of the Cathedral of the old town of Caserta have been analysed. The vault was modelled as a thin shell made of Rigid Non-Tension material. The webs of the vault under investigation were supported on two crossing ribs. To obtain the axial force inside the ribs, equilibrated and singular stress fields have been constructed. Estimates of the thrust forces transmitted by the vault to the peripheral arches and walls were also obtained to assess equilibrium. 
The paper by Fortunato (2016) is devoted to the application of unilateral models to identify the stress analysis of masonry structures. Two dimensional applications of the so called the simplified masonry-like model for masonry were studied. The main technique here employed for applying the No-Tension model to masonry was the systematic use of singular stress and strain fields within the frame set by the theorems of Limit Analysis. The authors highlighted that the unilateral model for masonry can be a useful tool for modelling real masonry structures. Also, tools introduced in this paper could potentially be implemented to construct computer codes for the structural analysis of masonry.

The wide range of experimental and computational techniques covered in this thematic issue, by authors from around the world, is indicative of the strong research interest in the area of structural masonry. Therefore, it is reasonable to assume that masonry construction will continue to excite the interest and captivate engineers and researchers for many years to come. In the future, it is expected that particular attention will be given to the behaviour of historic masonry structures and especially to the investigation of their seismic vulnerability using digital techniques and state of the art monitoring equipment. With the use of advanced computational methods of analysis and the increase in computer power and big data handling, exciting models could be developed at different scales of analysis.

As the Guest Editor of the special issue on Advances in Masonry Materials and Structures: Experimental \& Numerical Modelling Aspects at the Open Construction and Building Technology Journal, I would like to genuinely thank all authors participating in it as well as the international panel of reviewers of the submitted manuscripts which made the publication of this special issue possible. Moreover, I would like to thank the Editor of the Open Construction and Building Technology Journal, Panagiotis G Asteris, for all the support and guidance during the preparation and execution of this task.

Vasilis Sarhosis

School of Civil Engineering and Geosciences, Newcastle University, Newcastle upon Tyne, NE1 7RU, UK Email: vasilis.sarhosis@newcastle.ac.uk 